\title{
OS DIREITOS SOCIAIS NA CONSTITUIÇÃO DE WEIMAR COMO \\ PARADIGMA DO MODELO DE PROTEÇÃO SOCIAL DA ATUAL CONSTITUIÇÃO FEDERAL BRASILEIRA
}

\author{
SOCIAL RIGHTS IN THE CONSTITUTION OF WEIMAR AS A PARADIGM OF THE SOCIAL \\ PROTECTION PATTERN IN THE BRAZILIAN FEDERAL CONSTITUTION
}

Denise Auad*

\begin{abstract}
Resumo:
Este trabalho parte do modelo proposto pela Constituição de Weimar em relação à positivação dos direitos fundamentais de natureza social para compreender o atual paradigma de proteção brasileiro. Considera que as diretrizes constitucionais referentes aos direitos de segunda geração obriga o Estado a engendrar todos os seus esforços para concretizar políticas públicas como suporte de efetivação desses direitos.
\end{abstract}

Palavras-chave: Direitos Sociais. Constituição de Weimar. Políticas públicas. Direitos Humanos.

\begin{abstract}
:
This paper bases on the standard proposed by Constitution of Weimar regarding the positivation of fundamental rights that have a social feature in order to understand the present paradigm of Brazilian protection. It considers that the constitutional directives regarding the second-generation rights oblige the State to make all efforts to constitute policies as a support to effective those rights.
\end{abstract}

Keywords: Social rights. Weimar Constitution. Public policies. Human rights.

1. O papel histórico da Constituição de Weimar e os direitos sociais

A Constituição de Weimar, a qual instituiu a Primeira República alemã, foi promulgada em 1919, fruto da Pós-Primeira Guerra Mundial, o qual foi um período bastante conturbado para a sociedade alemã, que, desestabilizada pela derrota na guerra, buscava a reconstrução de suas instituições, fator que era dificultado pelos inúmeros compromissos impostos à Alemanha pelos países vitoriosos com a assinatura do Tratado de Versalhes. ${ }^{1}$

\footnotetext{
Doutora pelo Departamento de Direito do Estado da Faculdade de Direito da Universidade de São Paulo.

1 Pelo Tratado de Versalhes, assinado em 28 de junho de 1919, a Alemanha foi proibida de manter a Marinha e a Aeronáutica e ficou obrigada a pagar aos países vencedores uma indenização de, aproximadamente, trinta e três bilhões de dólares, além de renunciar a todas as suas colônias da Ásia e da África, bem como a entregar o Porto de Dantzig à Polônia e às regiões da Alsácia e da Lorena à França. O objetivo era enfraquecer a Alemanha militarmente e economicamente para impedir que se restabelecesse como potência, o que ameaçaria o equilíbrio de forças européias imposto pelos países vencedores da Primeira Guerra Mundial.
} 
Neste cenário, o próprio espírito da Constituição alemã, de 1919, nasce enfraquecido. A imprecisão quanto à aplicação de seus dispositivos, em conseqüência, não pode ser imputada ao texto constitucional, mas à ambigüidade dos valores reais, vigentes no seio de uma sociedade em crise que não sabia qual o arranjo de forças políticas possibilitaria a reconstrução da unidade do Estado. Ressalta-se que os dispositivos da Constituição eram inovadores e propunham um caminho coerente para alcançar uma unidade democrática por meio da implementação de direitos de ordem social.

A História, todavia, é implacável e sempre nos deixou a lição de que um povo só respeita sua Constituição se efetivamente acreditar em seus valores, o que significa que o sucesso da normatividade do texto constitucional vai muito além de seu processo de positivação, pois retira sua força da dinâmica presente no cotidiano das relações sociais. Assim, a Constituição materialmente aplicada pode estar muito distante da Constituição formal, prevista pelo legislador.

A sociedade alemã da época de Weimar estava pulverizada em grupos de interesses contrapostos, fator que refletia no enfraquecimento do Estado e atingia diretamente a ordem constitucional. Sheri Berman descreve essa realidade e aponta, inclusive, que tal fragmentação social foi a principal responsável pelo colapso da República de Weimar e pela escolha de um modelo totalitário de Estado, o qual conseguiu "vender" o sonho da reconstrução nacional ao convencer a sociedade alemã que este era o único caminho possível para o fortalecimento da Nação:

The vigor of German civil society actually developed in inverse relation to the vigor and responsiveness of national political institutions and structures. Instead of helping to reduce social cleavages, Germany's weak and poorly designed political institutions exacerbated them; instead of responding to the demands of an increasingly mobilized population, the country's political structures obstructed meaningful participation in public life. As a result, citizens' energies and interests were deflected into private associational activities, which were generally organized within rather than across group boundaries. The vigor of civil society activities then continued to draw public interest and involvement away from parties and politics, further sapping their strength and significance. Eventually, the Nazis seized the opportunities afforded by such situation, offering a unifying appeal and bold solutions to a nation in crisis. ${ }^{2}$

O texto constitucional de Weimar está dividido em duas partes. A primeira

2 BERMANN, Sheri. Civil society and the collapse of the Weimar Republic. World Politics, Princeton, v. 49, n. 3, p. 401-429, apr. 1997. 
trata da estrutura administrativa do "Reich" e dos Poderes Estatais. A segunda dispõe sobre os direitos e as obrigações do povo alemão, dentre os quais os de natureza social, como, por exemplo, a educação, a saúde, a proteção à infância e à maternidade e a dignidade da relação trabalhista. Foi justamente essa segunda parte que gerou mais polêmica, porque abria caminhos para a inserção social de camadas excluídas da população, o que significava, no fundo, a mudança do status social vigente à época, a qual decorreria da distribuição de riquezas decorrente da reforma social que a segunda parte da Constituição proporcionaria. Alguns autores, como Herman Heller, apontam, inclusive, que a Constituição alemã, de 1919, seria um caminho de transição pacífica para a construção do Estado Social, de bases marxistas, o qual superaria definitivamente o modo de produção capitalista.

No modelo de Weimar, a efetivação de direitos sociais tornou-se uma responsabilidade do Estado de natureza constitucional, possível de ser cobrada institucionalmente. A abertura do Parlamento à participação política das classes sociais menos privilegiadas, as quais passaram a exigir direitos de igualdade com mais força, em contraposição aos interesses da elite econômica dominante, que reivindicava manutenção de seu status quo, transformou o Poder Legislativo em alvo de severas críticas:

Carl Schmitt, em sua obra A Crise da Democracia Parlamentar critica duramente o Parlamento ao apontá-lo como um órgão desestruturado e composto por facções particulares incapazes de garantir, politicamente, a unidade do Estado:
A situação do sistema parlamentar tornou-se hoje extremamente crítica, porque a evolução da moderna democracia de massas transformou a discussão pública, argumentativa, numa simples formalidade vazia... Os partidos (que de acordo com o texto da Constituição escrita nem existem oficialmente) atualmente não se apresentam mais em posições divergentes, com opiniões passíveis de discussão, mas sim como grupos de poder sociais ou econômicos, que calculam os interesses e as potencialidades de ambos os lados para, baseados nesses fundamentos efetivos, selarem compromissos e formarem coalizões". ${ }^{3}$

Continua o autor: "Com todo respeito a esses homens, hoje em dia ninguém mais compartilha da sua expectativa de garantir, por meio do Parlamento, a formação de uma elite política". ${ }^{4}$

Schmitt afirmava que a segunda parte da Constituição de Weimar não era dotada de aplicabilidade, já que não garantia um mínimo de conteúdo decisório ao

\footnotetext{
SCHMITT, Carl. A crise da democracia parlamentar. Tradução de Inês Lohbauer. São Paulo: Scritta, 1996. p. 08 .

4 Id. Ibid., p. 09.
} 
aplicador do Direito e, portanto, deveria ser desconsiderada do ordenamento jurídico. ${ }^{5}$

Foram visões como essa, de caráter conservador, que solaparam qualquer possibilidade de implantação real do modelo de inclusão social proposto pela República de Weimar. O diálogo em prol integração social e fortalecimento da democracia foram substituídos por um Estado Totalitarista que se instalou no poder com a promessa da integração nacional baseada na ideologia da segregação racial, e que dotou o partido nazista de poderes até mesmo mais amplos que o Estado. A conseqüência dessa política totalitária e segregatória foi nefasta para a humanidade e levou a um dos maiores massacres da História, o qual ficou conhecido por holocausto. Hannah Arendt, defensora da cultura de Weimar e uma das maiores estudiosas do holocausto, relata que o nazismo mostrou o que há de mais atroz e cruel na alma humana e que os homens devem se policiar para não criarem instituições ou modelos políticos que abram espaço para a arbitrariedade. Segundo a Autora, a Democracia ainda é o melhor regime para a garantia de um espaço público pautado no diálogo, capaz de propiciar a tolerância e promover o "direito a ter direitos".

Apesar de a vigência da Constituição de Weimar ter sido curta, representou um marco para o reconhecimento histórico dos direitos sociais como direitos fundamentais e complementares aos direitos civis e políticos. Weimar inspirou diversas Constituições de outros países e, no Brasil, em especial, inspirou a Constituição getulista, de $1934 .{ }^{6}$

A própria redação dos artigos que prevêem os direitos sociais na Constituição de Weimar representa um amadurecimento intelectual em relação à conscientização de que o bem-estar social é condição essencial que pressupõe a conquista dos demais direitos. A

\footnotetext{
Escreve Gilberto Bercovici sobre a opinião de Schmitt sobre a segunda parte da Constituição de Weimar: “... a segunda parte era uma segunda Constituição, um fragmento de outro tipo de Constituição, em oposição à neutralidade axiológica da Constituição própria do Estado Legislativo. Entre a neutralidade axiológica da primeira parte da Constituição (sistema de legalidade) e a acentuação axiológica das garantias de conteúdo material da segunda parte da Constituição, não poderia haver meio termo. Segundo Schmitt, a Constituição de Weimar estava literalmente dividida entre duas Constituições materiais dentro da mesma Constituição formal. Como não havia conexão da segunda parte com a primeira parte da Constituição, Schmitt denominou a segunda parte de Contra-Constituição". BERCOVICI, Gilberto. Constituição e Estado permanente: atualidade de Weimar. Rio de Janeiro: Azougue Editorial, 2004. p. 142.

6 Conforme aponta Fábio Konder Comparato: “Apesar das fraquezas e ambigüidades assinaladas, e malgrado a sua breve vigência, a Constituição de Weimar exerceu decisiva influência sobre a evolução das instituições políticas em todo o Ocidente. O Estado da democracia social, cujas linhas-mestras já haviam sido traçadas pela Constituição mexicana, de 1917, adquiriu na Alemanha, de 1919, uma estrutura mais elaborada, que veio a ser retomada em vários países após o trágico interregno nazifacista e a $2^{a}$ Guerra Mundial. A democracia social representou efetivamente, até o final do século $X X$, a melhor defesa da dignidade humana, ao complementar os direitos civis e políticos - que o sistema comunista negava - com os direitos econômicos e sociais, ignorados pelo liberal-capitalismo. De certa forma, os dois grandes Pactos internacionais de direitos humanos, votados pela Assembléia Geral das Nações Unidas, em 1966, foram o desfecho do processo de institucionalização da democracia social, iniciado por aquelas duas Constituições no início do século". COMPARATO, Fábio Konder. A afirmação Histórica dos Direitos Humanos. 3. ed. São Paulo: Saraiva, 2003. p. 188-9.
} 
leitura chega até a impressionar, dado o momento histórico de Weimar, pela ousadia de determinar, na ordem suprema do ordenamento jurídico, que o Estado é responsável pela prestação de serviços públicos que protejam a dignidade do homem.

A título de exemplo, vale mencionar algumas das disposições da segunda parte da Constituição alemã. O legislador constitucional expressamente prevê que homens e mulheres são iguais em direitos e obrigações (art. 109). Dedica o segundo capítulo para a "vida em comunidade", no qual elege a família como núcleo central da sociedade alemã, e a ela destina proteção especial. Afirma que as famílias grandes têm direito à proteção social do Estado e a legislação deve criar condições de igualdade para o desenvolvimento físico, espiritual e social de crianças nascidas fora do casamento, que a juventude deve ser protegida contra a exploração, contra desvios morais e espirituais, bem como contra a negligência. No mesmo capítulo, trata do direito ao trabalho digno, com ênfase ao serviço público, resguardando o direito de pensionistas e dependentes. No terceiro capítulo, garante a liberdade religiosa e a liberdade de consciência. No capítulo quarto, o qual trata da educação, determina que o Estado deve provê-la por meio de instituições públicas e que a escolarização é obrigatória e gratuita ${ }^{7}$ a partir dos 8 anos de idade até que o indivíduo complete 18 anos. ${ }^{8}$ Em relação à economia, prevista no capítulo cinco, dispõe que deve ser organizada com base nos princípios da justiça e com o objetivo de garantir dignidade a todas as pessoas, protege o direito de propriedade, mas afirma que pode ser limitado pela lei. No art. 145, permite a nacionalização de empresas por meio de regras para a expropriação e mediante justa indenização. Prevê, no art. 158, que o Reich deve proteger a criação intelectual, o direito de autor, de inventores e de artistas. Permite a organização sindical, estabelece um sistema de previdência social e, no art. 165, permite que os trabalhadores participem do planejamento da economia por meio de Conselhos.

Pelo exposto, fica nítida a preocupação do legislador de Weimar em prever um sistema de direitos sociais, o que reforça a importância do papel histórico dessa Constituição para o reconhecimento dos chamados direitos fundamentais de segunda geração.

2. As gerações de direitos fundamentais

Em primeiro lugar, cumpre esclarecer que a expressão "geração de direitos fundamentais" tem uma perspectiva didática para marcar o momento histórico em que

\footnotetext{
$7 \mathrm{O}$ art. 145 inclui o direito à gratuidade do material didático como parte do direito à educação.

8 Estabelece o art. 146: "A educação pública deve ser organizada de forma orgânica. O ensino médio e superior estão baseados no ensino elementar, comum para todos. Para a organização do sistema escolar, o determinante é a pluralidade das vocações, e, para a aceitação de uma criança na escola, são levadas em conta seu talento e inclinação, e não a posição econômica e social ou a crença religiosa de seus pais".
} 
tais direitos passam a ser reconhecidos pelo ordenamento jurídico de vários Estados ocidentais e adquirem status de norma constitucional. Entretanto, em nenhum momento tal expressão pode deixar dúvidas de que as gerações posteriores à primeira, relacionada aos direitos civis e políticos, possuem importância menor, visto que todas as gerações se complementam para a integralidade da proteção do ser humano.

Há, inclusive, um debate na doutrina que questiona se os direitos, quando passam a fazer parte do ordenamento jurídico, são meramente “declarados” ou, ao invés, se são criados a partir de sua positivação. Posicionamo-nos no sentido de que o Direito formal apenas declara os direitos fundamentais na medida em que os reconhece como normas postas, inclusive com status constitucional, já que são pressupostos ao Estado e possuem um núcleo apriorístico que integra a existência da humanidade, a qual os descobre (e os redescobre) de acordo com as necessidades de cada período histórico.

Atualmente, podemos apontar o reconhecimento, pela maioria dos ordenamentos jurídicos fundamentais, de três gerações de direitos fundamentais: os direitos civis e políticos, também chamados de liberdades públicas, os direitos sociais e econômicos e os direitos de solidariedade.

Os direitos civis e políticos são reconhecidos historicamente a partir do século XVIII, em decorrência das Grandes Revoluções Libertárias como a Independência NorteAmericana e a Revolução Francesa, as quais tinham como objetivo pôr fim à monarquia absolutista. São positivados como direitos que exigem o afastamento do Estado em relação ao indivíduo, para lhe garantir um espaço livre à autonomia privada. Nesse sentido, foram afirmados direitos para a proteção da propriedade, ${ }^{9}$ da segurança, para a garantia da liberdade de religião, de casamento, de expressão, de reunião, de associação, dentre outros. Representam o cerne das Constituições-Garantia, as quais, baseadas na Teoria da Separação de Poderes, fundamentaram a construção do liberalismo político ao longo dos séculos XVIII e XIX, principal pano-de-fundo para o fortalecimento da burguesia.

Já os direitos econômicos e sociais, de segunda geração, tiveram seu reconhecimento histórico apenas no século XX, por meio da Constituição mexicana de 1917, e, com maior abrangência, por meio da Constituição da República de Weimar, em 1919. ${ }^{10}$ São considerados direitos de prestação, por exigirem do Estado uma atuação positiva e a aplicação de verbas orçamentárias para sua concretização. Fazem parte desse rol os direitos trabalhistas, previdenciários, de amparo à saúde, à maternidade e o

\footnotetext{
9 Podemos apontar a Teoria do Contrato Social delineada por LOCKE, John. Segundo Tratado sobre o Governo Civil. Tradução de Jacy Monteiro. São Paulo: Ibrasa, 1963, como a base da idéia da propriedade como um direito natural, pertencente ao indivíduo e, portanto, pressuposto do direito positivado pelo Estado.

${ }^{10}$ Um marco histórico muito importante para os direitos de segunda geração, que enfatizou a sua importância no século XX, foi o Pacto Internacional sobre os Direitos Econômicos e Sociais da ONU, de 1966, o qual passou a vincular os Estados-Parte ao cumprimento de seus dispositivos.
} 
direito à educação. ${ }^{11}$ Os direitos econômicos e sociais são fruto de longas lutas históricas de reivindicação, por parte das classes proletárias e excluídas, de proteção estatal para a garantia, pelo menos, das condições necessárias para uma subsistência digna. Os direitos sociais apontam o reconhecimento, pelos diplomas constitucionais, de que não basta o Estado garantir liberdade aos seus cidadãos, pois esta não se consolida sem a garantia de um mínimo de dignidade social.

Recentes trabalhos que aprofundam o tema dos direitos fundamentais, a fim de lhes garantir maior completude, rompem com o paradigma que associa os direitos de primeira geração a uma abstinência do Estado e os de segunda geração, a uma prestação positiva do Estado. Esta é a preocupação, por exemplo, de Victor Abramovich e Christian Courtis, os quais explicam:

La distinción, sin embargo, es notoriamente endeble. Todos los derechos, llámense civiles, políticos, económicos o culturales tienen un costo, y prescriben tanto obligaciones negativas como positivas. Los derechos civiles no se agotan en obligaciones de abstención por parte del Estado: exigen conductas positivas, tales como la reglamentación-destinada a definir el alcance y las restricciones de los derechos - , la actividad administrativa de regulación, el ejercicio del poder de policía, la protección frente a las interferencias ilícitas del propio Estado y de otros particulares, la eventual imposición de condenas por parte del Poder Judicial en caso de vulneración, la promoción del acceso al bien que constituye el objeto del derecho. Baste repasar mentalmente la gran cantidad de recursos que destina el Estado a la protección del derecho de propiedad: a ello se destina gran parte de la actividad de la justicia civil y penal, gran parte de la tarea policial, los registros de la propiedad inmueble, automotor y otros registros especiales, los servicios de catastro, la fijación y control de zonificación y uso del suelo, etcétera. ${ }^{12}$

Os direitos de solidariedade, considerados de terceira geração, pelo fato de sua positivação ocorrer apenas a partir da metade do século XX, têm como característica

\footnotetext{
${ }_{11}$ A atual Constituição Federal Brasileira, de 1988, reconheceu os direitos sociais especialmente nos arts. $6^{\circ}$ e $7^{\circ}$, os quais apontam o seguinte rol de direitos: educação, saúde, trabalho, lazer, segurança, previdência social, proteção à maternidade e à infância e assistência aos desamparados. $\mathrm{O}$ art. $7^{\circ}$ apresenta uma lista de trinta e quatro incisos, todos relacionados a direitos trabalhistas. A questão que se coloca é a seguinte: a enumeração dos direitos, apresentada pelos arts. $6^{\circ}$ e $7^{\circ}$ da Constituição, seria numerus clausus ou um rol aberto? Entendemos que, pela importância da dimensão da proteção dos direitos sociais, devemos entender tal lista como aberta, possível de incorporar outros direitos que compartilhem do mesmo espírito de promoção da dignidade humana.

12 ABRAMOVICH, Victor; COURTIS, Christian. Apuntes sobre la exigibilidad judicial de los Derechos Sociales. In: SARLET, Ingo Wolfgang (Org.). Direitos Fundamentais Sociais: Estudos de Direito Constitucional, Internacional e Comparado. Rio Janeiro/São Paulo: Renovar, 2003. p. 135.
} 
a heterogeneidade e a titularidade difusa. São frutos da atual sociedade de massa, na qual as demandas passam a ter muito mais uma natureza coletiva do que individual. Como exemplo de tais direitos, podemos citar o meio ambiente sustentável, o patrimônio genético, a autodeterminação dos povos, o direito à paz e ao desenvolvimento, dentre outros. Os principais instrumentos que veiculam esses direitos são os Tratados Internacionais, inclusive com mais ênfase que a própria Constituição dos Estados, fator que pode ser explicado pelo fenômeno da globalização, o qual amplia o espaço público de litígio entre as pessoas, por colocar em contato povos de culturas diferentes e por gerar direitos e deveres que transcendem as fronteiras nacionais. Apesar do maior grau de complexidade, os direitos de terceira geração também podem ser compreendidos à luz das explicações de Victor Abramovich e Christian Courtis, por demandar do Estado tanto obrigações positivas quanto negativas, a fim de complementar a unidade do sistema de proteção dos direitos fundamentais.

3. Os direitos sociais como normas programáticas e a Constituição dirigente

Em primeiro lugar, cabe fazer uma diferenciação entre o conceito de normas programáticas e o de Constituição Dirigente. Aquelas são normas que conduzem os órgãos estatais a realizar direitos sociais como uma meta do Estado, o qual deve garantir, por meio desses direitos, uma condição de vida digna a seus cidadãos. Já a Constituição Dirigente é o veículo que contém as normas programáticas e que, portanto, as dota de status constitucional e, como conseqüência, parametriza as decisões políticas dentro de valores sociais que devem ser perquiridos pelo Estado. ${ }^{13}$

As normas programáticas são alvo de críticas no sentido de que prevêem direitos que não podem ser imediatamente exigidos. No entanto, conforme apontam Victor Abramovich e Christian Courtis, tais críticas, muitas vezes, não passam de preconceitos vazios:

Gran parte de la tradición constitucional iberoamericana en

\footnotetext{
${ }^{13}$ CANOTILHO, J. J. Gomes. Direito constitucional e teoria da Constituição. 4. ed. Almedina, 2000. p. 464-66, aponta quatro possibilidades de conformação jurídica dos direitos sociais. A primeira seria as "normas sociais" como normas programáticas, conforme já explicado acima. A segunda seria as "normas sociais" como normas de organização, no sentido de atribuir competência, a qual obrigaria o legislador a regulamentar os direitos sociais. A terceira classificação considera as "normas sociais" como garantias institucionais, que orientam os aplicadores do Direito na aplicação da lei e da Constituição para a efetivação dos direitos sociais. Por fim, a última classificação considera as "normas sociais" como direitos subjetivos públicos, os quais permitem aos cidadãos cobrar do Estado sua prestação. Não-obstante tal classificação, preferimos, neste trabalho, utilizar a expressão "normas programáticas" para apontar a conformação jurídico-constitucional dos direitos sociais, não apenas pelo peso histórico dessa expressão, mas, também, pela possibilidade de pressionar os órgãos estatais a planejarem um programa social, que, obrigatoriamente, deve ser o referencial das decisões políticas do Estado.
} 
materia de derechos sociales se caracteriza por la repetición de tópicos que, a luz de la experiencia internacional y de la ya considerable acumulación de precedentes nacionales, han demostrado ser prejuicios de tipo ideológico, antes que argumentos sólidos de dogmática jurídica. Así, aunque la gran mayoría de las Constituciones de América Latina, la de España y la de Portugal estén alineadas dentro del denominado constitucionalismo social, se ha repetido hasta el hartazgo que las normas que establecen derechos sociales son sólo normas programáticas, que no otorgan derechos subjetivos en el sentido tradicional del término, o que no resultan justiciables. De este modo, se traza una distinción entre el valor formativo de los denominados derechos civiles - o derechos de autonomía, o derechos-libertades -, que sí se consideran derechos plenos, y los derechos sociales, a los que asigna un mero valor simbólico o político, pero poca virtualidad jurídica. ${ }^{14}$

Pelo exposto, o primeiro passo para a efetivação dos direitos sociais é a desmistificação de que suas normas são apenas previsões políticas, cujo cumprimento depende do total alvitre do Poder Executivo. ${ }^{15}$ Para que este passo se consolide, mister compreender o papel que a Constituição Dirigente possui para balizar a conduta do administrador.

A Constituição Dirigente tem a função de orientação axiológica para traçar limites às ações do Poder Executivo. ${ }^{16}$ Portanto, este não pode agir arbitrariamente, ou implementar um programa político pautado exclusivamente em suas convicções pessoais ou de seu partido político, haja vista que as linhas gerais de seu plano de Governo devem estar de acordo com as diretrizes previamente estabelecidas pelo Poder Constituinte Originário.

Ressalte-se que em nenhum momento a Constituição Dirigente elimina o poder discricionário ${ }^{17}$ intrínseco à política, apenas coloca limites valorativos para a conduta

\footnotetext{
14 ABRAMOVICH, Vctor; COURTIS, Christian. Apuntes sobre la exigibilidad judicial de los Derechos Sociales. In: SARLET, Ingo Wolfgang (Org.). Direitos Fundamentais Sociais: Estudos de Direito Constitucional, Internacional e Comparado. Rio Janeiro/São Paulo: Renovar, 2003. p. 136.

15 “Afirma-se, hoje, em geral na doutrina, o caráter vinculativo das normas programáticas. Significa que o fato de dependerem de providências institucionais para sua realização não quer dizer que não tenham eficácia”. José Afonso da SILVA. Aplicabilidade das normas constitucionais programáticas. Revista da Procuradoria Geral do Estado, Fortaleza, v. 9, n. 11, p. 43-60, 1992.

${ }^{16}$ Estamos enfatizando a responsabilidade do Poder Executivo para o cumprimento da Constituição pelo fato de ser o agente, de natureza primária, responsável pela efetivação de políticas públicas, já que o texto constitucional lhe outorga diretamente competências jurídicas para tal. No entanto, é importante ressaltar que as normas constitucionais, por serem as regras supremas do ordenamento jurídico de um Estado, condicionam as condutas tanto do Poder Público, quanto do setor privado, ou seja, de toda a sociedade.

17 Conceitua o jurista Hely Lopes Meirelles: "Poder discricionário é o que o Direito concede à Administração, de modo explícito ou implícito, para a prática de atos administrativos com liberdade na escolha de sua
} 
do administrador, os quais são plenamente legítimos, pois consolidados pelo legislador originário, o único que tem poder para estabelecer os princípios da organização jurídica fundamental do Estado.

\section{Conforme explica Gilberto Bercovici:}

A Constituição dirigente não estabelece uma linha única de atuação para a política, reduzindo a direção política à execução dos preceitos constitucionais, ou seja, substitui a política. Pelo contrário, ela procura, antes de mais nada, estabelecer um fundamento constitucional para a política, que deve mover-se no âmbito do programa constitucional. Dessa forma, a Constituição dirigente não substitui a política, mas se torna a sua premissa material. O poder estatal é um poder com fundamento na Constituição, e seus atos devem ser considerados constitucionalmente determinados. Inclusive, ao não-regular inúmeras questões (afinal, nenhuma Constituição pode-se pretender completa ou perfeita), cabe à discussão política solucioná-las. A função da Constituição dirigente é a de fornecer uma direção permanente e consagrar uma exigência de atuação estatal. ${ }^{18}$

Outro fator que enfraquece a obrigatoriedade do cumprimento das normas programáticas é a alegação de que dependem de um aporte financeiro do Estado para se efetivarem, argumento este que já serviu de desculpa para muitos governantes se eximirem por completo de sua responsabilidade social. A falta de verbas pode ser um fator limitante, mas jamais um obstáculo intransponível.

Há que se ponderar, também, que o principal Poder Público responsável pelo planejamento e pela execução orçamentária é Executivo e, para isso, está obrigado a direcionar esforços políticos para a consecução dos direitos sociais. Tomando-se como exemplo a atual Constituição Federal brasileira, podemos citar o art. 165, o qual determina:

Leis de iniciativa do Poder Executivo estabelecerão:

conveniência, oportunidade e conteúdo". (MEIRELLES, Hely Lopes. Direito administrativo brasileiro. 22. ed. São Paulo: Malheiros Editores, 1997. p. 102.

18 BERCOVICI, Gilberto. A problemática da Constituição dirigente: algumas considerações sobre o caso brasileiro. Revista de informação Legislativa, Brasília, v. 36, n. 142, p. 35-51, abr./jun. 1993, p. 40. Continua o referido Autor: "A definição dos fins do Estado não pode nem deve derivar da vontade da política conjuntural dos governos. Os fins políticos supremos e as tarefas do Estado encontram-se normatizados na Constituição. Afinal, a Constituição legitima o poder político do Estado. O programa constitucional não tolhe a liberdade do legislador ou a discricionariedade do Governo, nem impede a renovação da direção política e a confrontação partidária. Essa atividade de definição de linhas de direção política tornou-se cumprimento dos fins que uma república democrática constitucional fixou em si mesma. Cabe ao Governo selecionar e especificar sua atuação a partir dos fins constitucionais, indicando os meios ou instrumentos adequados para a sua realização". Ibid., p. 40-1. 
I - o plano plurianual;

II - as diretrizes orçamentárias;

III - os orçamentos anuais.

$\S 1^{\circ}$ - A lei que instituir o plano plurianual estabelecerá, de forma regionalizada, as diretrizes, objetivos e metas da administração pública federal para as despesas de capital e outras delas decorrentes e para as relativas aos programas de duração continuada.

$\S 2^{\circ}$ - A lei de diretrizes orçamentárias compreenderá as metas e prioridades da administração pública federal, incluindo as despesas de capital para o exercício financeiro subseqüente, orientará a elaboração da lei orçamentária anual, disporá sobre as alterações na legislação tributária e estabelecerá a política de aplicação das agências financeiras oficiais de fomento.

O próprio argumento do contingenciamento das verbas orçamentárias não pode ser um argumento definitivo para a não-realização de políticas públicas. Tomando-se novamente o exemplo do ordenamento jurídico brasileiro, podemos citar o $\S 2^{\circ}$ do art. $9^{\circ}$ da Lei de Responsabilidade Fiscal (Lei Complementar n. 101, de 04 de maio de 2000), o qual determina:

$\S 2^{\circ}$ Não serão objeto de limitação as despesas que constituam obrigações constitucionais e legais do ente...

Assim, a Constituição Federal brasileira está delimitando políticas públicas obrigatórias quando expressamente afirma que: "A saúde é direito de todos e dever do Estado" (art. 196), "O dever do Estado com a educação será efetivado mediante a garantia de: ensino fundamental, obrigatório e gratuito, assegurada, inclusive, sua oferta gratuita para todos os que a ele não tiveram acesso na idade própria” (art. 208, I), "É dever da família, da sociedade e do Estado assegurar à criança e ao adolescente, com absoluta prioridade, o direito à vida, à saúde, à alimentação, à educação, ao lazer, à profissionalização, à cultura, à dignidade, ao respeito, à liberdade e à convivência familiar e comunitária, além de colocálos a salvo de toda forma de negligência, discriminação, exploração, violência, crueldade e opressão" (art. 227).

Tais políticas devem necessariamente ser efetivadas independentemente de qual governante ou partido político esteja no poder e, além disso, suas verbas não podem ser contingenciadas conforme dispõe a própria Lei de Responsabilidade Fiscal em seu art. $9^{\circ}, \S 2^{\circ}$. Ressalta-se que a desobediência aos comandos da Lei Complementar n. 101/04 gera, também, a possibilidade de impeachment, segundo o art. 85, VI da Constituição 
Federal. $^{19}$

Portanto, o verdadeiro instrumento para a realização dos direitos sociais chama-se "interesse político", com força suficiente para conduzir o Estado dentro dos parâmetros constitucionais e legais em prol da realização do bem-comum.

É por tal motivo que o sucesso de uma política pública depende intrinsecamente da conscientização do povo em relação a ela, ou seja, do embate das forças reais que formam os arranjos de poder de um determinado Estado. É esse arranjo que determina, concretamente, qual é a prioridade de uma determinada sociedade. Enquanto o povo não se conscientizar da importância da efetivação dos direitos sociais como uma necessidade pressuposta para a dignidade do corpo social, tais direitos continuarão, na prática, como "dispensáveis".

4. O papel dos poderes estatais para a efetivação dos direitos sociais

A delimitação criteriosa do campo de atuação de cada um dos Poderes do Estado, ou seja, do Poder Legislativo, do Poder Executivo e do Poder Judiciário em relação à efetivação dos direitos sociais, contribui para a obtenção de políticas públicas com mais qualidade.

Começando pelo Poder Legislativo, seja o legislador constitucional ou o ordinário, podemos apontar que sua principal tarefa nesse mister é a delimitação jurídica dos direitos sociais. ${ }^{20}$ Essa é uma tarefa essencial, pois as políticas públicas estão atreladas ao princípio da legalidade, já que o Poder Executivo, mesmo dotado de poder discricionário, deve pautar seus atos nos comandos normativos.

No entanto, as normas programáticas nos colocam diante de um desafio. A delimitação do conteúdo da norma deve balizar a conduta do administrador público, sem, no entanto, retirar-lhe a liberdade de escolha política decorrente de seu poder discricionário. Todavia, a margem da delimitação normativa não pode ser vaga a ponto de impedir a efetivação do próprio direito previsto. Segundo lição de Victor Abramovich e Christian Courtis:

...cabe señalar que los problemas de falta de especificación del contenido de un derecho son típicos de las normas constitucionales o de tratados de derechos humanos, dado que se trata de las normas de mayor nivel de generalidad

\footnotetext{
19 Dispõe o art. 85 da Constituição Federal brasileira de 1988: "São crimes de responsabilidade os atos do Presidente da República que atentem contra a Constituição Federal e, especialmente, contra: VI - A lei orçamentária".

${ }^{20}$ O Novo Código Civil brasileiro, Lei n. 10.406, de 10 de janeiro de 2002, é um exemplo da adoção de valores sociais pelo legislador ordinário, ao conceber um conjunto de normas de natureza principiológica e absorver, em alguns de seus artigos, princípios constitucionais como a função social da propriedade e da empresa.
} 
del orden jurídico. Múltiples razones militan a favor de esta generalidad: permite mayor flexibilidad y adaptabilidad a instrumentos formativos..., ofrece a los órganos encargados de especificar el contenido de los derechos contenidos en esos instrumentos un margen de elección compatible con la prudencia y necesidad de evaluación de la oportunidad que requiere la toma de cualquier decisión política, preserva la brevedad y concisión que hacen de estos documentos el catálogo de principios fundamentales del estado de derecho. ${ }^{21}$

Como o Poder Legislativo é o que está mais próximo da representação da vontade do povo, pois expressa essa vontade por meio da elaboração do ordenamento jurídico, parte dele a tarefa de balizar os direitos sociais que uma determinada sociedade entende como essenciais em um determinado período histórico, que, então, servirão de parâmetro tanto para o Poder Executivo, quanto para o Poder Judiciário. O grau de sensibilidade do Poder Legislativo determinará o conteúdo exato da delimitação normativa, para dar potencialidade à eficácia dos direitos sociais.

Já o Poder Executivo desempenha tarefa essencial para a implementação dos direitos sociais, pois é ele o principal responsável pela realização de políticas públicas.

Para a efetivação das políticas públicas, o Poder Executivo tem competência para o exercício do Poder de Polícia, o qual consiste tanto no poder de regulamentação dos direitos, quanto em sua fiscalização. A maioria dos direitos sociais não se realizaria sem o aparato de uma consistente regulação administrativa. Veja-se, por exemplo, o caso do direito à saúde. Não basta que o texto constitucional garanta que a saúde é direito de todos e dever do Estado, pois as pessoas não serão adequadamente atendidas pelos estabelecimentos médico-hospitalares se não houver uma minuciosa regulação para permitir a instalação e o funcionamento desses estabelecimentos. A tarefa da regulação é complementada pelo dever de fiscalização, o qual garante à população um padrão adequado para a prestação dos serviços públicos.

A deficiência do Poder Executivo em relação à implementação de políticas públicas pode ocorrer tanto por uma ação quanto por uma omissão. Em relação à postura do Estado que causa lesão a direitos (ação), a doutrina se ampara nas teses da responsabilidade objetiva, as quais garantem o ressarcimento dos prejuízos com a comprovação da lesão. Mais delicado, no entanto, são os casos que envolvem a omissão do Poder Executivo a ponto de prejudicar a efetivação de direitos sociais. A omissão pode ser parcial, quando o Estado presta o serviço, mas de maneira incompleta - por exemplo, quando mantém

\footnotetext{
${ }^{21}$ ABRAMOVICH, Vctor; COURTIS, Christian. Apuntes sobre la exigibilidad judicial de los Derechos Sociales. In: SARLET, Ingo Wolfgang (Org.). Direitos Fundamentais Sociais: Estudos de Direito Constitucional, Internacional e Comparado. Rio Janeiro/São Paulo: Renovar, 2003. p. 156-7.
} 
uma rede pública para o atendimento à saúde, mas tal rede não é suficiente para garantir um atendimento adequado aos usuários - ou, então, a omissão pode ser total, quando o ente estatal deixa de prover por completo um direito social previsto em seu ordenamento jurídico. Atualmente, a maioria dos casos, como reflexo da falência do modelo do Estado do Bem-Estar Social, estão relacionados à omissão parcial da prestação de direitos sociais, ou seja, o Estado tem o aparato institucional para o atendimento, mas, no entanto, este não é suficiente para suprir as demandas pelo serviço.

As modernas teorias de Direito Administrativo já delineiam teses no sentido de aplicar a responsabilidade do Estado inclusive para os casos de omissão, seja total, ou parcial, que lesem direitos sociais, desde que se comprove que o Estado deixou de atuar adequadamente, embora tivesse condições para tal. Isso significa que o Estado poderá ser punido se deixar de aplicar todos os esforços possíveis para responder integralmente às demandas sociais. Na prática, o grande desafio é a mensuração desses "esforços possíveis", função esta de competência preponderante do Poder Judiciário, quando for acionado para julgar o grau de deficiência do serviço público prestado. ${ }^{22}$

As limitações decorrentes da falência do Estado de Bem-Estar Social geraram inúmeras reformas administrativas que seguiram a tendência de cooptação do setor privado como um parceiro do Estado para a prestação de serviços públicos. Decorre daí o fortalecimento do Terceiro Setor como agente ampliador da rede de serviços públicos disponíveis. ${ }^{23}$ Alerta-se, no entanto, que o sucesso dessas reformas só ocorrerá se o setor privado atuar apenas de forma complementar ao Estado e não-substitutiva, já que a responsabilidade pelo planejamento macro das políticas públicas, bem como sua implementação são tarefas essencialmente estatais.

O Poder Judiciário assume, hoje, portanto, um papel essencial para a equalização das demandas sociais. Nele, estão depositadas as esperanças para obrigar o Estado a efetivar direitos sociais.

A atuação do Poder Judiciário, no entanto, também está atrelada aos modelos de ação disponibilizados pela legislação processual estatal. Este fator também é um desafio, haja vista que o aparato judiciário tradicional está adequado para solucionar conflitos decorrentes da violação de direitos civis e políticos, o que garante uma proteção mais efetiva das liberdades públicas em detrimento dos direitos sociais. É recente a incorporação legal de ações para a proteção mais abrangente dos direitos sociais, e, dentre elas, podemos mencionar a) a ação civil pública, b) a ação que tenha por objeto o

\footnotetext{
${ }^{22}$ O Poder Judiciário precisa estar capacitado para cumprir, com êxito, essa função, o que implica a necessidade de o magistrado possuir sólidos conhecimentos sobre o funcionamento da Administração Pública, bem como sobre a execução das verbas orçamentárias.

23 No Brasil, a Lei de Parceria Público-Privado é um exemplo claro dessa tendência reformista.
} 
cumprimento de obrigação de fazer ou não-fazer, ${ }^{24} \mathrm{c}$ ) o mandado de segurança coletivo e d) a ação direta de inconstitucionalidade por omissão.

O poder de interpretação final das normas jurídicas também é atribuído ao Poder Judiciário. Assim, será a partir dessa atividade interpretativa, a qual conduz à produção jurisprudencial, que poderemos diagnosticar o grau de comprometimento do Poder Judiciário em relação à efetivação dos direitos sociais, ou seja, se atua com mais timidez ou de forma mais inovadora. Entretanto, é inegável o poder de pressão que o Judiciário possui para obrigar os demais órgãos públicos a prever, implementar e respeitar os direitos sociais.

As sentenças que julgam procedente a efetivação de direitos sociais são alvo, entretanto, de severas críticas relacionadas à Teoria da Separação de Poderes. Os principais argumentos nessa linha apontam que a elaboração de políticas públicas não é uma função típica do Poder Judiciário, o qual deve se restringir ao julgamento de possíveis lesões a direito decorrentes do descumprimento das políticas previamente traçadas pelo Poder Executivo. Nesse sentido, quando uma sentença obriga o Estado a efetivar um direito social, estaria, automaticamente, interferindo na aplicação das verbas do orçamento público ao escolher uma política pública em detrimento da vontade do administrador público.

Apesar desse argumento encontrar defensores, entendemos que, intrinsecamente, possui um erro lógico. Vejamos: em primeiro lugar, o poder discricionário do Executivo não é sinônimo de poder arbitrário, ou seja, o administrador público tem margem de liberdade para atuar dentro dos limites traçados, em primeiro lugar, pela Constituição. Se esta determina ao Estado o cumprimento de determinados direitos sociais, então as políticas públicas que os respaldam têm prevalência em face de outras políticas formuladas pelo Governo. Neste caso, o Executivo não tem faculdade para escolher, pois está obrigado a efetivar os direitos fundamentais previstos pelo texto constitucional. No Brasil, é o caso, por exemplo, do direito à educação e à saúde, bem como das políticas públicas voltadas à infância, à juventude e aos idosos. Se o Executivo deixar de garantir, adequadamente, com todos os seus esforços possíveis, a realização desses direitos, será plenamente possível ao cidadão lesado pela omissão acionar o Judiciário para que o direito

\footnotetext{
${ }^{24}$ De acordo com o art. 461 do Código de Processo Civil brasileiro: "Na ação que tenha por objeto o cumprimento de obrigação de fazer ou não fazer, o juiz concederá a tutela específica da obrigação, ou, se procedente o pedido, determinará providências que assegurem o resultado prático equivalente ao do adimplemento". Tal dispositivo contribui para a efetivação dos direitos sociais, pois determina o cumprimento da obrigação ou um resultado prático equivalente, não aceitando a mera indenização por perdas e danos no caso de inadimplemento. $\mathrm{O} \S 3^{\circ}$ do referido artigo reforça a efetivação da obrigação, ao ampliar o poder do juiz para pressionar nesse sentido, já que pode aplicar multa diária ao réu, independentemente de pedido do autor.
} 
lhe seja proporcionado adequadamente. ${ }^{25}$

\section{Conclusão}

A Constituição de Weimar abriu as portas para a positivação dos direitos sociais, dando-lhes status de norma constitucional, o que foi muito importante para iniciar um processo de conscientização, no mundo ocidental, de que a dignidade humana deve ser garantida pelo Estado; caso contrário, todas as outras disposições de seu ordenamento jurídico restarão prejudicadas.

No entanto, é paradoxal contrapor essa conscientização com a realidade concreta dos Estados. A importância dos direitos sociais é um consenso no plano da teoria; todavia, a prática sinaliza um caminho inverso, ou seja, o aumento da exclusão social e da concentração da riqueza. Apesar dos avanços tecnológicos da modernidade, ainda há, por exemplo, muitas pessoas morrendo de fome no mundo, não pelo fato de não haver alimento suficiente para todos, mas, simplesmente, pelo fato de não possuírem renda para comprar comida. O problema está, portanto, em nossa própria organização social, a qual, na prática, visa muito mais ao lucro, à competição, ao consumo desenfreado do que ao bem-estar humano. Daí porque os discursos de defesa dos direitos sociais incomodam tanto quando há a possibilidade de se tornarem reais.

O episódio de Weimar sinalizou o quanto a sociedade ainda está imatura para a implementação de uma ordem social mais justa, haja vista que, quando a Alemanha teve a possibilidade de escolher um modelo democrático pela via reformista, contida em sua Constituição, de 1919, decidiu pela manutenção dos privilégios das elites econômicas, mesmo às custas da criação de um Estado totalitário, supressor, inclusive das liberdades individuais. ${ }^{26}$ Ressalta-se, também, que a Constituição de Weimar foi apontada como a

\footnotetext{
${ }^{25}$ Recentes julgados no Brasil compartilham com a visão de que o Poder Judiciário é um agente ativo para determinar o cumprimento de direitos sociais:

"O agente político pode definir melhor a forma de executar a lei, mas não pode deixar de cumpri-la sob qualquer pretexto. A lei constitui limite ao exercício do poder discricionário. Se desobedecer aos ditames legais, a conduta ativa ou omissiva fica sujeita ao controle judicial.

Em outras palavras, o respeito ao princípio da conveniência e oportunidade da Administração Pública não pode merecer conceito tão lato que permita ao governante decidir se cumpre a lei. No caso, a discricionariedade do ato estará a salvo com a liberdade de decidir como atenderá a demanda...

Afasta-se, assim, a visão de que as garantias sociais contidas na norma constitucional (...) explicitam comandosvalores de caráter programático, não passíveis de imediata exigibilidade junto ao Poder Judiciário". Agravo de Instrumento n. 104.316-0/0-00 - Rel. Des. Viseu Júnior, 24/11/2003, Eg. Câmara Especial do Tribunal de Justiça do Estado de São Paulo.

26 "Em 1930, apesar da defesa da Constituição de Weimar feita por Hermann Heller, a catástrofe social da crise econômica mundial atingiu a República de Weimar e a sua Constituição e a crise econômica se tornou uma crise do Estado. No mesmo ano, Richard Thoma descrevia a democracia da Constituição de Weimar como, simultaneamente, uma 'grande democracia', uma 'democracia pobre' graças às condições sociais da população alemã, uma 'democracia oprimida' pela pobreza e pelo desemprego e uma 'democracia ameaçada', com uma
} 
"culpada" pelos problemas políticos da Alemanha. ${ }^{27}$

Transferindo essa lição histórica para o Brasil e comparando a Constituição de Weimar à Constituição Federal brasileira, de 1988, podemos perceber situações semelhantes. $\mathrm{O}$ modelo constitucional brasileiro atual também prioriza a realização de reformas sociais para a construção de um Estado mais justo, ${ }^{28}$ mas encontra barreiras na crise econômica e institucional em que o País está mergulhado. A situação brasileira ainda tem a agravante de o País ser periférico, ou seja, frágil diante da conjuntura política e econômica das grandes potências internacionais.

Há inúmeros discursos que defendem o retrocesso dos avanços sociais consolidados na Constituição, de 1988, como é o caso dos argumentos "chavão" que sustentam a flexibilização de importantes conquistas trabalhistas, sob o enfoque de que são uma "camisa de força" para o desenvolvimento do setor privado. A Constituição de 1988, copiosamente, é apontada como culpada pela "ingovernabilidade" e pela crise econômica que o País enfrenta, e o que é pior, como o único fator responsável pela instabilidade social. No entanto, o cotidiano brasileiro reluz um cidadão cada vez mais aviltado em seus direitos e oprimido pela imposição de um "laissez faire, laissez passer" à moda brasileira.

Como tudo isso é parecido com a realidade de Weimar! A democracia brasileira ainda é muito frágil e não podemos nos olvidar disso. Uma preocupação desponta dessa reflexão: Pode o Brasil optar por seguir o mesmo caminho que a Alemanha seguiu na década de 30 e procurar resolver seus problemas pela via do autoritarismo? A escolha desta opção seria um grande erro, pois a História já mostrou à humanidade o terrível sofrimento que a supressão dos Direitos Fundamentais acarreta, tanto que a Alemanha suporta até hoje as conseqüências do nazismo e buscou retomar um processo de desenvolvimento social com base em valores democráticos.

A democracia, apesar de todas as críticas que recebe, ainda é o regime inabalável para o respeito aos Direitos Fundamentais, ao pluralismo, à proteção das minorias, ao diálogo político e, principalmente, à promoção da tolerância. A efetivação de direitos sociais dentro de um regime democrático não é uma concessão, uma dádiva ou um presente do Estado, mas sim uma conquista do povo, um direito inviolável.

rebelião fascista que se armava secretamente". BERCOVICI, Gilberto. Constituição e Estado Permanente. cit., p. 138-9.

${ }^{27}$ Conforme aponta Gilberto Bercovici: "As alternativas conservadoras eram todas de cunho autoritário, com a atribuição de mais poderes ao presidente do Reich e a marginalização do Parlamento. Todas atribuíam à Constituição de Weimar, com seu Estado de partidos pluralista, a responsabilidade pela crise alemã. Estes autores, com Carl Schmitt à frente, defendiam, no fundo, a dissolução constitucional e a implementação de um regime ditatorial". Id. Ibid., p. 141.

${ }^{28}$ Determina o art. $3^{\circ}$ da CF/88: "Constituem objetivos fundamentais da República Federativa do Brasil: I construir uma sociedade livre, justa e solidária; II - garantir o desenvolvimento nacional; III - erradicar a pobreza e a marginalização e reduzir as desigualdades sociais e regionais; IV - promover o bem de todos, sem preconceitos de origem, raça, sexo, cor, idade e quaisquer outras formas de discriminação". 
A dignidade humana tem seu ponto inicial na garantia do suprimento das necessidades básicas de subsistência, aliada à garantia de o ser humano se desenvolver integralmente. Nesse sentido, os principais instrumentos que viabilizam essa condição são os direitos sociais, os quais devem ser prestados principalmente pelo Estado, sob pena de os interesses coletivos se transformarem em reivindicações setorizadas que priorizariam questões individuais em detrimento do coletivo. A construção do aparato estatal deve ter como finalidade a persecução do bem comum, pois, sem esta finalidade, deixa de ter sentido a própria existência do Estado. Assim, pode-se afirmar que o principal papel do Poder Público não é aquele previsto nas Constituições-garantia, na qual está limitado à função de polícia das liberdades públicas, mas, sim, o de equalizar as demandas sociais para o bem-estar do ser humano. Por isso, arriscamos até em afirmar que os direitos de segunda geração, senão iguais, são até "relativamente" mais importantes do que os direitos de primeira ou de terceira geração, já que, na verdade, são o pressuposto para a própria existência (e sobrevivência) digna do homem.

A República Weimar nos trouxe uma lição, não sejamos indolentes a ponto de deixar de aprendê-la!

São Paulo, março de 2008.

\section{Referências}

ABRAMOVICH, Victor; COURTIS, Christian. Apuntes sobre la exigibilidad judicial de los Derechos Sociales. In: SARLET, Ingo Wolfgang (Org.). Direitos fundamentais sociais: estudos de direito constitucional, internacional e comparado. Rio de Janeiro/São Paulo: Renovar, 2003.

ARENDT, Hannah. The origins of Totalitarism. New York: Harcourt, 1951.

ARON, Raymond. Démocratie et Totalitarisme. Paris: Gallimard, 1965.

BARRETO, Vicente de Paulo. Reflexões sobre os direitos sociais. In SARLET, Ingo Wolfgang (Org.). Direitos fundamentais sociais: estudos de direito constitucional, internacional e comparado. Rio de Janeiro/São Paulo: Renovar, 2003.

BERCOVICI, Gilberto. A Constituição Dirigente e a crise da Teoria da Constituição. In: Teoria da Constituição: Estudos sobre o lugar da política no Direito Constitucional. Rio de Janeiro: Lumen Juris, 2003.

- Constituição e Estado Permanente: atualidade de Weimar. Rio de Janeiro: Azougue Editorial, 2004.

. A problemática da Constituição dirigente: algumas considerações sobre o caso brasileiro. Revista de informação Legislativa, Brasília, v. 36, n. 142, p. 35-51, abril/junho 1993. 
BERMAN, Sheri. Civil society and the collapse of the Weimar Republic. World Politics, Princeton, v. 49, n. 03, p. 401-429, apr. 1997.

BONAVIDES, Paulo. Teoria do Estado. 3. ed. rev.e ampl. São Paulo: Malheiros Editores, 1995.

CANOTILHO, José Joaquim Gomes. Constituição dirigente e vinculação do legislador: contributo para a compreensão das normas constitucionais programáticas. Coimbra: Coimbra Editora, 1994.

. Direito Constitucional e Teoria da Constituição. 4. ed. Almedina, s.d.

COMPARATO. A afirmação histórica dos Direitos Humanos. 3. ed. São Paulo: Saraiva, 2003.

HELLER, Hermann. Estado de derecho o dictadura? Escritos Políticos. Madrid: Alianza Editorial, 1985.

. Teoria del Estado. Tradução Luis Tobío. 2. ed., 2. reimpr. México: Fondo de Cultura Economica, 2002.

JACOBSON, Arthur J.; SCHLINK, Bernhard (Eds.). Weimar: a jurisprudence of crisis. Translated by Belinda Cooper. Berkeley/Los Angeles/London: University of Califórnia Press, 2000.

LOCKE, John. Segundo Tratado sobre o Governo. Tradução de Jacy Monteiro. São Paulo: Ibrasa, 1963.

MEIRELLES, Hely Lopes. Direito administrativo brasileiro. 22. ed. São Paulo: Malheiros Editores, 1997.

SCHMITT, Carl. A crise da democracia parlamentar. Tradução de Inês Lohbauer. São Paulo: Scritta, 1996.

. La defensa de la Constitucion. Tradução de Manuel Sanchez Sarto. 2. ed. Madrid: Tecnos, 1998.

. Teoria de la Constitución. Tradução de Francisco Ayala. Madrid: Alianza Editorial, 1982.

SILVA, José Afonso da. Aplicabilidade das normas constitucionais programáticas. Revista da Procuradoria Geral do Estado, Fortaleza, v. 9, n. 11, 1993.

. Curso de direito constitucional positivo. 15. ed., rev. São Paulo: Malheiros Editores, 1998.

WEIMAR CONSTITUTION. Disponível em $<$ http://www.zum.de/psm/weimar/weimar_vve.php>. Acesso em: 10 abr. 2005. 